\title{
Enhanced Low Voltage Ride through Capability for Grid Connected Wind Energy Conversion System
}

\author{
Mohammed Alsumiri ${ }^{\text {a,1,*, Raed Althomali }}$ b,2 \\ a,b Electrical and Electronics Engineering Department, Yanbu Industrial College, Yanbu, Saudi Arabia \\ 1 alsumiri@rcyci.edu.sa, ${ }^{2}$ althomalir@rcyci.edu.sa \\ * Corresponding Author
}

ARTICLE INFO

Article History

Received 05 September 2021

Revised 06 September 2021

Accepted 02 October 2021

\section{Keywords}

Grid Connected;

Low-Voltage Ride Through;

PMSG;

Residue control;

Wind Energy Conversion System

\section{ABSTRACT}

It is obvious that the current era has received much attention in the fields of science and technology, besides the continuous endeavor to provide environmentally friendly and resource-saving alternatives for conventional energy conversion systems. The rapid development of Wind Energy Conversion Systems (WECS) has made Permanent Magnet Synchronous Generator (PMSG) a primer choice because of its advantages. The current trend on WECS necessitates wind turbines to maintain continuous operation during voltage drops, which is referred to as Low Voltage Ride Through (LVRT). The PMSG control technique is a widely used approach for improving conversion efficiency as well as LVRT capability. This paper provides LVRT and power enhancement for grid-connected PMSG based WECS using control techniques. The LVRT capability has been investigated by using PI and Residue controllers. The simulation results show improved active power delivery and better LVRT capability during voltage dips when the Residue controller is implemented.

This is an open access article under the CC-BY-SA license.

\section{Introduction}

Recently, penetration of wind energy has emerged significantly due to several aspects such as free availability of wind, environmental friendly nature and land space utilization (offshore) [1]. The relative high power extracting ability for WECS is also a key in WECS research attention [20]. Recently, large-scale PMSG based WECS has been widely integrated into the grid which makes the stability of operation a point of concern [13]. The discontinuity of power in large scale generation has severe impact on stable operation during transients and steady-states. Hence, the wind generator has to maintain the power and withstand the voltage disturbance [7]. It has become necessary for any WECS control to obtain LVRT during faulty conditions [9]. In order to achieve LVRT capability, it has been recommended to integrate the PMSG based WECS to into the grid via full scale power converter [27]. However, the LVRT enhancement could be obtained either by protection system in which hardware is used or improving the control strategy [2] [4]. Several techniques have been developed for obtaining LVRT. For better transient response a PI based current control has been proposed in [5]. It has been concluded that using current feedforward method enhanced the LVRT. For the nonlinear control of the GSC in a PMSG, a feedback linearization controller was developed in [6][15]. 
Some researchers considered connecting energy storage systems to WECS for helping the integration into the grid and makes the WECS more cost efficient [17]. Energy storage can assist WECS as an LVRT solution and it could result in enhanced the LVRT response compared to control implementation [12][16]. The initial employment of mathematical residue theorem in control system has been proposed in [10][11]. The error definition has been improved be considering the residue equation [18]. The control strategy set a boundary around the reference and forces the operating point to lie inside the boundary. Also, the controller has a better ability in handling the uncertainty. WECS are characterized as a nonlinear feedback plant with parameter uncertainties [21]. Many control techniques have been developed to improve WECS behavior and reported in literature [22][23][24][25][26].

This research paper concluded that SMC has improve the dynamic system behaviors in terms of robustness and uncertainty handling. However, the WECS dynamic performance using residue controller shows better ability in robust operation and handling the uncertainties [11][15]. In this paper the residue based control is implemented to a grid WECS to enhance and improve the energy conversion and LVRT capability. The control strategy is implemented. The proposed control technique shows a significant contribution in the field of WECS control. Using the proposed control would enhance both the voltage ride-through ability of the WECS and overall system robustness.

\section{WECS Overview}

The examined WPGS, which is shown in Fig. 1, employed a horizontal axial wind turbine (HAWT) driven directly by a sinusoidal back-EMF PMSG. The generated power delivered to the grid using energy storage devices and back-to-back power converter [29]. The wind power is directly proportional to the cube of wind speed [8][30]. However, the wind turbine extracts aerodynamic power from the wind as below [10]:

$$
\begin{aligned}
P & =\frac{1}{2} \pi \rho R^{2} C_{p}(\lambda) v^{3} \\
\lambda & =\frac{\omega R}{v}
\end{aligned}
$$

Where, $\rho$ is the air density, $R$ is the blade radius, $\pi R^{2}$ is the swept are (A), $C_{p}$ is the power coefficient and $v$ is the wind speed. $\lambda$ is the tip speed ratio which is the ratio of rotor speed $\omega$ and wind speed.

\subsection{Direct driven PMSG}

The PMSG can be represented in the dq-synchronous reference frame. The d-axis is aligned with the magnet axis, and the q-axis is orthogonal to the d-axis with respect to the direction of rotation [8]. The representation of the PMSG in the $d q$ synchronous reference is shown as below:

$$
\begin{aligned}
& V_{d}=R_{s} i_{d}+L_{d} \frac{d i_{d}}{d t}-\omega_{e} L_{q} i_{q}, \\
& V_{q}=R_{s} i_{q}+L_{q} \frac{d i_{q}}{d t}+\omega_{e}\left(L_{d} i_{d}+\psi_{P M}\right)
\end{aligned}
$$

Where vd and vq are the dq-axis voltages, $R_{d}$ and $R_{q}$ are the d-q stator resistances, $L$ is the stator inductance, $\omega_{e}$ is the electrical angular speed and $\psi_{P M}$ is the flux linkage. 
The mechanical behavior of the PMSG can be described as the following:

$$
\begin{aligned}
& T_{m}=T_{e}+I \frac{d \omega}{d t}+B \omega, \\
& \omega_{e}=p \omega, \\
& T_{e}=1.5 p\left(\psi_{P M} i_{q}+\left(L_{d}-L_{q}\right) i_{d} i_{q}\right)
\end{aligned}
$$

Where, $T_{m}$ and $T_{e}$ are the mechanical and electrical torque respectively, $p$ is the pole pairs, $J$ is the inertia and $B$ denotes the friction.

\subsection{Power Converter}

The generated power from the PMSG is supplied to the grid through two back-to-back voltage source converter [28]. In fact, these converters are of three-phase two-level PWM converters with DC link. Fig. 1 illustrates the power converters configuration. The generated AC power is rectified through the machine side converter. The PWM is modulated in order to implement PMSG field oriented control. Through the grid side converter, the DC link power is inverted to AC ensuring grid synchronism [14].

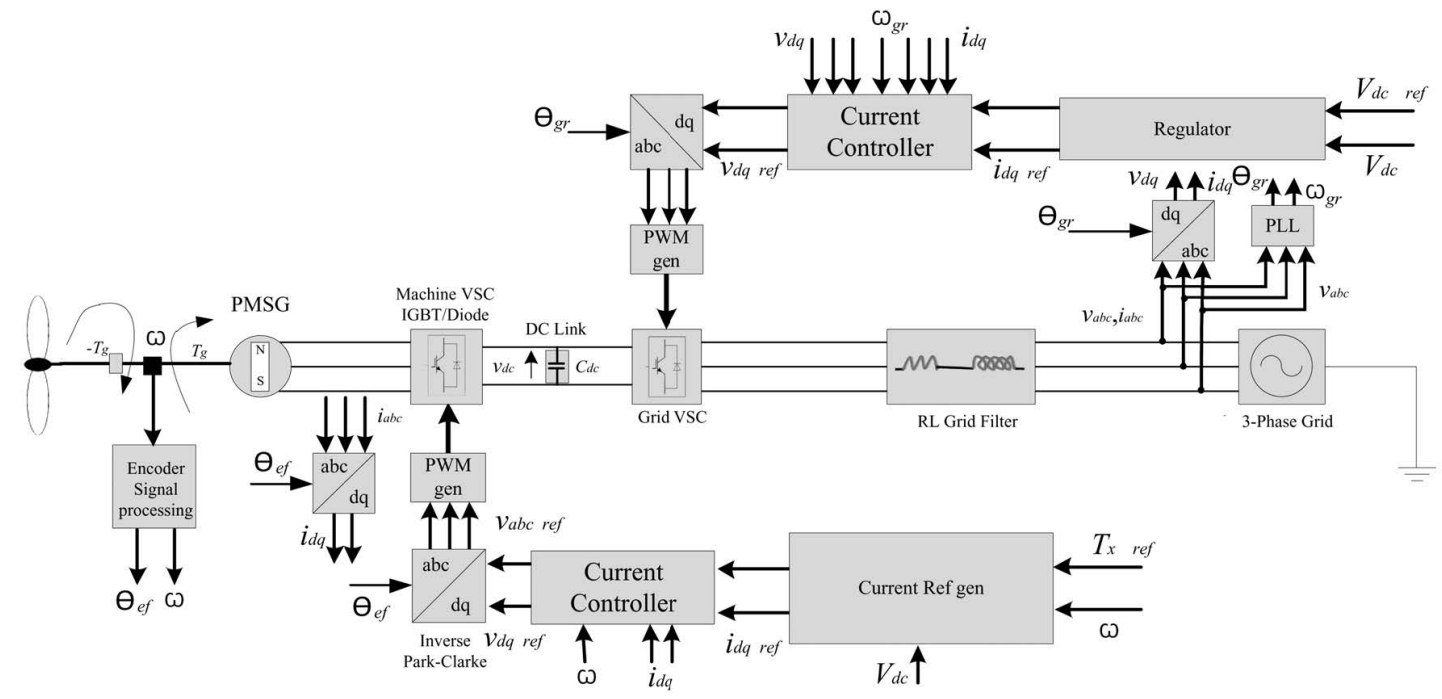

Fig 1. Configuration of the investigated direct driven grid connected WECS

The current controller ensures the current is controlled to its reference level so that the speed is maintained to ensure the maximum power point operation is reached. It is well known that the filter is placed to minimise the harmonics injection to the grid system.

\section{Control System Design}

\subsection{Conventional PI Control}

The PI controller technique has been developed to examine and evaluate the WECS dynamics especially LVRT capability and to allow the controller evaluation with Residue-PI control strategies. In WECS application, the PI controller has been employed to PMSG after removing the cross-coupling between the $\mathrm{d}$-axis and q-axis circuits. The linear model after adding the decoupling voltages, which removes the cross-coupling to improve the system dynamic performance to the system can be shown in [2][3]. The structure of the PI controller can be shown as follows [8]: 


$$
G(s)=k_{p}+\frac{k_{i}}{s}
$$

The closed loop transfers functions of the speed control, the d-axis and q-axis currents control can be shown in Fig. 2, which illustrates the linearized model of a PMSG with PI speed and current controllers. The PI controllers have been developed for both of the power converters.

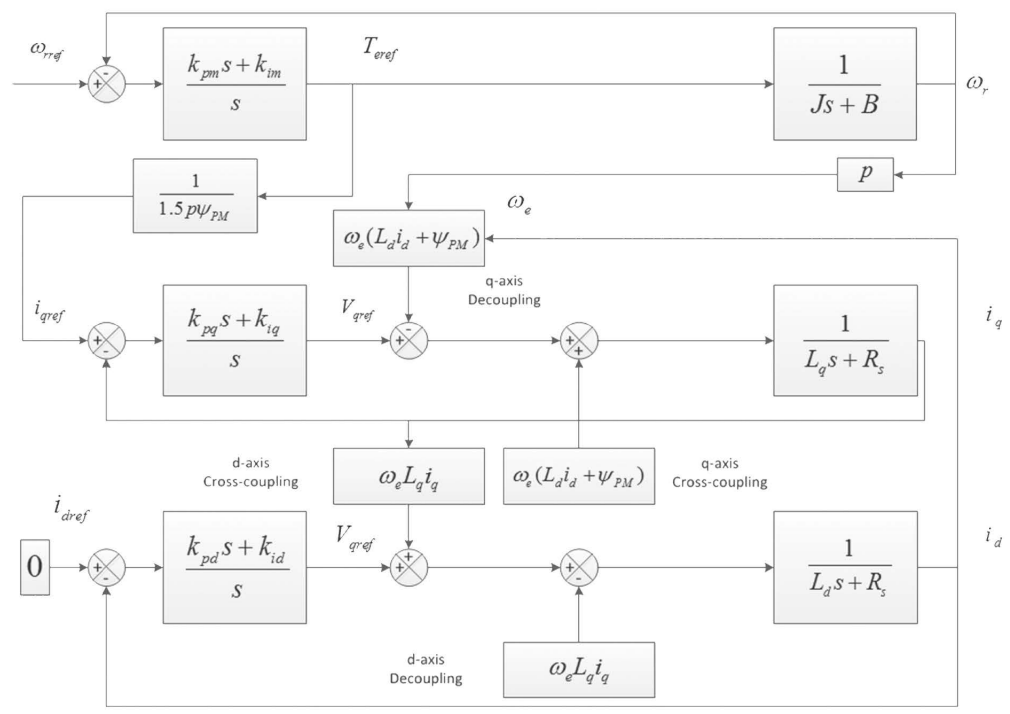

Fig 2. Linearize PMSG model

\subsection{Mathematical Residue-PI control}

The mathematical residue controller has been developed and implemented for both the power converters. The residue based control employed redefines the error $e$ to be a new value $e_{r}$ [19]. The boundary area is selected to be between a reference point plus the absolute value of the error and the reference point minus the absolute value of the error. The error (e) is the difference between the reference point and the actual measured point of speed. Following Forward-Euler Equation for ensuring the stability and the achievement of the operating point. The control block could be expressed as below [8][9]:

$$
\begin{aligned}
\dot{e_{r}} & =e+c, \\
e_{r} & =\frac{e^{2}}{2}+c e . \\
\dot{x} & =\operatorname{Res}(x), \\
\dot{x} & =\frac{x e_{r}}{\pi} .
\end{aligned}
$$

where, $c$ is constant gain and $x$ is the controlled variable. 


\section{Simulation Results and Analysis}

In this research article, the examined WECS is a horizontal axial wind turbine (HAWT), and the generator is a PMSG. The WECS model has been simulated on rated wind speeds. The grid fault starts at $\mathrm{t}=20 \mathrm{~s}$ and remains for $1 \mathrm{~s}$. The parameters of the PMSG and the HAWT employed in this simulation are illustrated in the Table 1.

The model has been simulated using MATLAB/Simulink. The dynamic performance for the WECS have been compared using PI control and residue-PI control. Figure 3 shows the DC link voltages under the two control techniques. It is clear from the figure that the DC link voltage shows constant and stable operation when residue-PI control is employed. The impact of the grid fault is clearly appearing on the DC link voltage performances. However, the percentage change on the DC link voltage is less when residue-PI control is employed. The less the change in voltage the less the rate of change in current.

The active power delivered by the WECS is illustrated in Fig. 4. The power generation improvement is clearly shown in the figure. Using residue-PI control technique enhances the power capability of the WECS. Also, the robust and continuous operation is clearly shown in the figure. The continuity of power is enhanced significantly during grid failure which protects the PMSG from the surge current. Fig. 5 demonstrates the pu PMSG voltage under both the residue-PI control and PI control. Also, the grid pu voltage is shown and the fault is shown. The stator voltages withstand the grid fault safely. The PMSG speed is inspected as well. Fig. 6 shows the rotor pu speed. Both controllers have the ability of maintaining constant speed operation and the machine can reject the influence of grid fault robustly.

Table 1. WECS parameters.

\begin{tabular}{|l|l|l|}
\hline Parameter & Value & Unit \\
\hline HAWT nominal Power & 1.5 & $M W$ \\
HAWT nominal wind speed & 12 & $m \backslash s$ \\
PMSG inertia & P35000 & $\mathrm{Kgm}^{2}$ \\
PMSG friction & $0.01 \mathrm{t}$ & $\mathrm{Nm} \mathrm{s}$ \\
PMSG flux linkage & 1.48 & $\mathrm{~Wb}$ \\
PMSG phase resistance & 0.06 & $\Omega$ \\
PMSG dq-axis inductances & 0.3 & $\mathrm{mH}$ \\
DC link capacitor & 10 & $\mathrm{mF}$ \\
\hline
\end{tabular}

\section{Conclusions}

In this research, a grid connected large scale direct-driven PMSG based WECS has been investigated. A control technique has been developed based on mathematical Residue control. The controller has been tested and tuned to enhanced the overall system dynamics. Also, a conventional PI controller has been developed for the system in order to compare the system dynamic performance.It can be concluded that using residue-PI control could overcome the uncertainty handling issues that is clearly appears when PI control is implemented. However, the system tuning and disturbance rejection is improved which leads to more efficient system. The aim of the control besides maintaining robust operation is to enhance the power capability and the LVRT. The WECS has been investigated during grid faults and the system dynamics have been evaluated using the two control techniques.The residue-PI control shows better dynamic performance ability for WECS during steady-states and transients. It would be highlighted that by using residue-PI control the WECS power generation ability is maximized and the LVRT is en- 


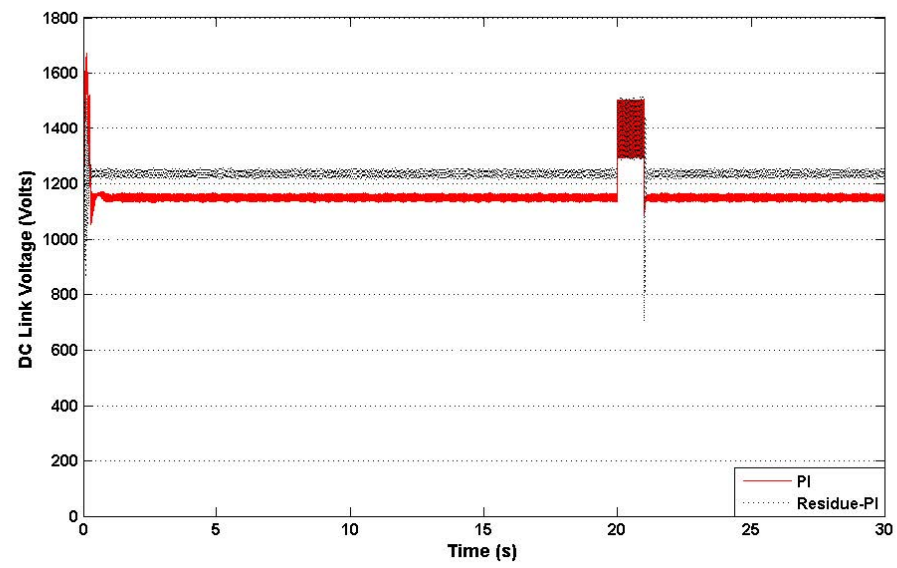

Fig 3. DC Link Voltages.

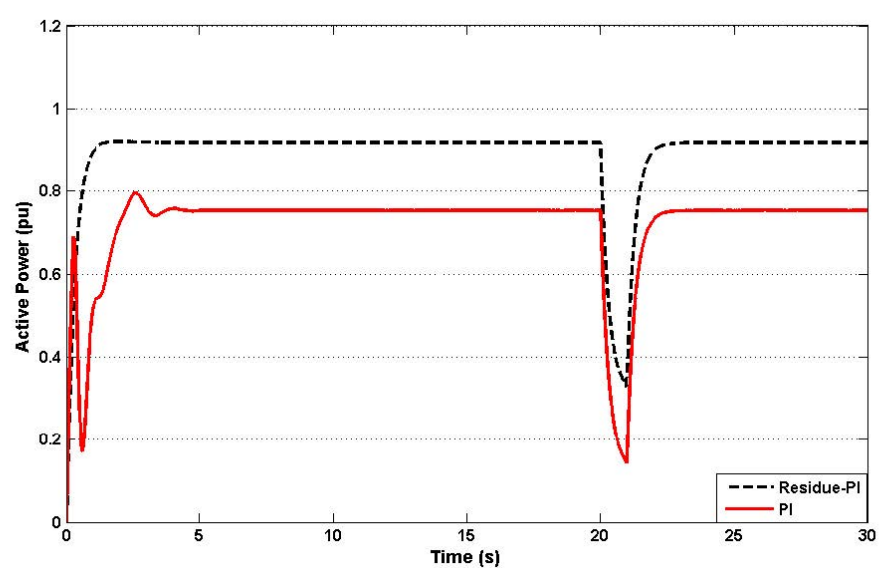

Fig 4. Active pu Power delivered by WECS.

hanced.

\section{References}

[1] J. Dai, D. Xu, and N. R. Zargari, "Unified DC-link current control for low-voltage ride-through in current-source-converter-based wind energy conversion systems," IEEE Transactions on Power Electronics, vol. 26, no. 1, pp. 288-297, 2011. https://doi.org/10.1109/TPEL.2010.2059377

[2] M. Ding and Q. Zhu," Equivalent modeling of PMSG-based wind power plants considering LVRT capabilities: electromechanical transients in power systems," SpringerPlus, vol. 5, p. 2037, 2016. https://doi.org/10.1186/s40064-016-3700-5

[3] S. Xia, Q. Zhang, S. T. Hussain, B. Hong, and W. Zou, "Impacts of integration of wind farms on power system transient stability," Applied Sciences, vol. 8, no. 8, p. 1289, 2018. https://doi.org/10.3390/ app8081289

[4] C. Kim and W. Kim, "Coordinated fuzzy-based low-voltage ride-through control for pmsg wind turbines and energy storage systems," IEEE Access, vol. 8, pp.105874-105885, 2020. https://doi.org/ 10.1109/ACCESS.2020.3000247

[5] D. P. Ke, C. Y. Chung and Y. Xue, "Controller design for DFIG-based wind power generation to damp interarea oscillation," In 2010 5th International Conference on Critical Infrastructure (CRIS), pp. 

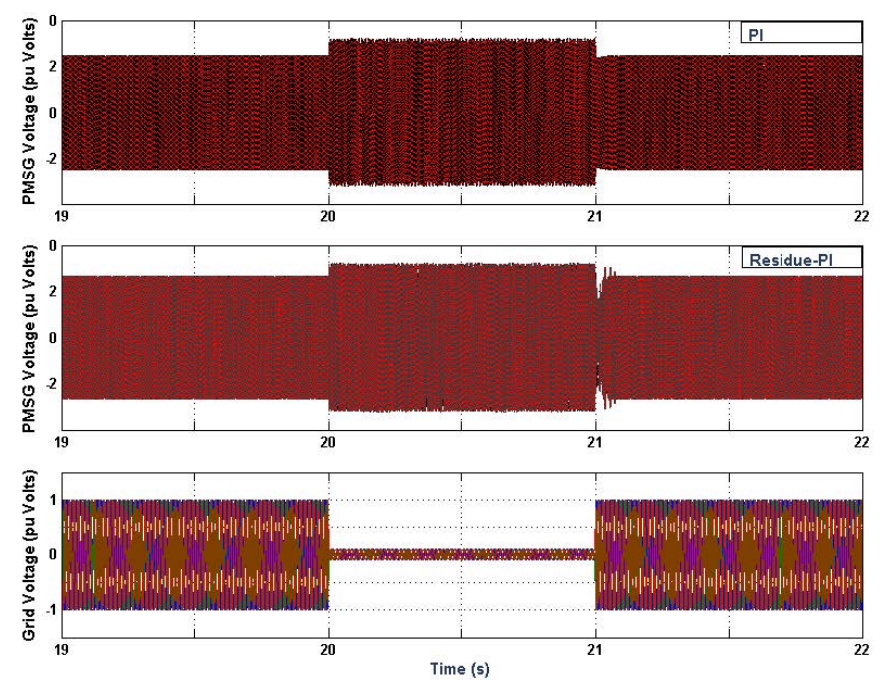

Fig 5. Grid and stator pu Voltages

\section{1-6, IEEE, 2010. https://doi.org/10.1109/CRIS.2010.5617574}

[6] S. W. Xia, S. Q. Bu, X. Zhang, Y. Xu, B. Zhou, and J. B. Zhu "Model reduction strategy of doubly-fed induction generator-based wind farms for power system small-signal rotor angle stability analysis." Applied energy, vol. 222, pp. 608-620, 2018. https://doi.org/10.1016/j.apenergy.2018.04.024

[7] M. R. Islam, J. Hasan, M. N. Huda and M. A.H. Sadi, "Fault Ride Through Capability Improvement of DFIG Based Wind Farms Using Active Power Controlled Bridge Type Fault Current Limiter," 2019 North American Power Symposium (NAPS), 2019, pp. 1-6. https://doi.org/10.1109/NAPS46351. 2019.9000292

[8] A. Jalilian, S. B. Naderi, M. Negnevitsky, M. T. Hagh, and K. M. Muttaqi, "Controllable DC-link fault current limiter augmentation with DC chopper to improve fault ride-through of DFIG," IET Renewable Power Generation, vol. 11, no. 2, pp. 313-324, 2017. https://doi.org/10.1049/iet-rpg.2016.0146

[9] D. Baimel, N. R. Chowdhury, J. Belikov and Y. Levron. "New type of bridge fault current limiter with reduced power losses for transient stability improvement of DFIG wind farm," Electric Power Systems Research, vol. 197, 2021. https://doi.org/10.1016/j.epsr.2021.107293

[10] M. Marei, H. El-Goharey and Randa M. Toukhy. "Fault ride-through enhancement of fixed speed wind turbine using bridge-type fault current limiter," Journal of Electrical Systems and Information Technology, vol. 3, no. 1, pp. 119-126, 2016. https://doi.org/10.1016/j.jesit.2016.01.002

[11] O. P. Mahela, N. Gupta, M. Khosravy and N. Patel, "Comprehensive Overview of Low Voltage Ride Through Methods of Grid Integrated Wind Generator," IEEE Access, vol. 7, pp. 99299-99326, 2019. https://doi.org/10.1109/ACCESS.2019.2930413

[12] M. Ding and Q. Zhu, " Equivalent modeling of PMSG-based wind power plants considering LVRT capabilities: electromechanical transients in power systems," SpringerPlus, vol. 5, no. 1, 2016. https: //doi.org/10.1186/s40064-016-3700-5

[13] S. Xia, Q. Zhang, S. T. Hussain, B. Hong, and W. Zou," Impacts of integration of wind farms on power system transient stability," Applied Sciences, vol. 8, no. 8, pp. 1289, 2018. https://doi.org/10.3390/ app8081289

[14] C. Kim and W. Kim, " Coordinated fuzzy-based low-voltage ride-through control for pmsg wind turbines and energy storage systems," IEEE, vol. 8, pp. 105874-105885, 2020. https://doi.org/10. 1109\%2Faccess.2020.3000247

[15] G. Saccomando, J. Svensson and A. Sannino, "Improving voltage disturbance rejection for variablespeed wind turbines," IEEE Transactions on Energy Conversion, vol. 17, no. 3, pp. 422-428, 2002. https://doi.org/10.1109/TEC.2002.801989 


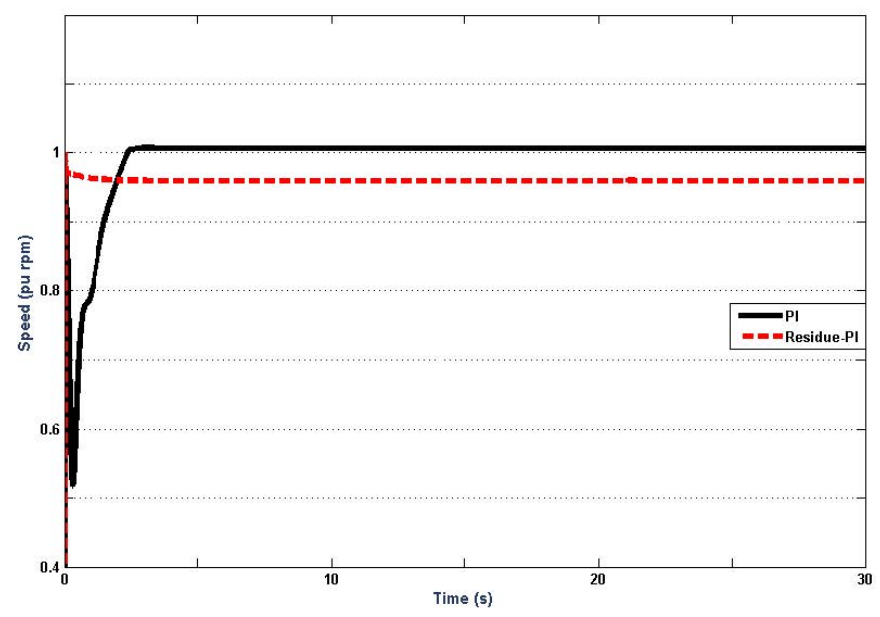

Fig 6. Rotor speed using PI and Residue-PI control.

[16] A. Mullane, G. Lightbody and R. Yacamini, "Wind-turbine fault ride-through enhancement," IEEE Transactions on Power Systems, vol. 20, no. 4, pp.1929-1937, 2005. https://doi.org/10.1109/ TPWRS.2005.857390

[17] J. Kim, E. Muljadi, V. Gevorgian and A. F. Hoke, "Dynamic capabilities of an energy storage-embedded DFIG system," IEEE Transactions on Industry Applications, vol. 55, no. 4, pp. 4124-4134, 2019. https: //doi.org/10.1109/TIA.2019.2904932

[18] M. Alsumiri, L. Li, L. Jiang, and W. Tang, "Residue theorem based soft sliding mode control for wind power generation systems," Protection and Control of Modern Power Systems, vol. 3, no. 1, 2018. https://doi.org/10.1186/s41601-018-0097-x

[19] M. Alsumiri, "Residual Incremental Conductance Based Nonparametric MPPT Control for Solar Photovoltaic Energy Conversion System," IEEE Access, vol. 7, pp. 87901-87906, 2019. https://doi.org/ 10.1109/ACCESS.2019.2925687

[20] J. Baran and A. Jąderko, "An MPPT Control of a PMSG-Based WECS with Disturbance Compensation and Wind Speed Estimation," Energies, vol. 13, no. 23, p. 6344, 2020. https://doi.org/10.3390/ en13236344

[21] T. D. Do, "Disturbance observer-based fuzzy SMC of WECSs without wind speed measurement," IEEE Access, vol. 5, pp.147-155, 2016. https://doi.org/10.1109/ACCESS.2016.2633271

[22] A. Watil, A. El Magri, A. Raihani, R. Lajouad, and F. Giri, "Multi-objective output feedback control strategy for a variable speed wind energy conversion system," International Journal of Electrical Power \& Energy Systems, vol. 121, p. 106081, 2020. https://doi.org/10.1016/j.ijepes.2020.106081

[23] F. Golnary and H. Moradi, "Dynamic modelling and design of various robust sliding mode controls for the wind turbine with estimation of wind speed," Applied Mathematical Modellings, vol. 65, pp. 566-585, 2019. https://doi.org/10.1016/j.apm.2018.08.030

[24] S. N. Vukosavic, "Grid-Side Converters Control and Design," Springer, 2018. https://doi.org/10. 1007/978-3-319-73278-7

[25] N. Nguyen, A. Bera, and J. Mitra,"Energy Storage to Improve Reliability of Wind Integrated Systems under Frequency Security Constraint," IEEE Transactions on Industry Applications, vol. 54, no. 5, pp. 4039-4047, 2018. https://doi.org/10.1109/TIA.2018.2838558

[26] C. Kim and W. Kim, "Low-Voltage Ride-Through Coordinated Control for PMSG Wind Turbines Using De-Loaded Operation," IEEE Access, vol. 9, pp. 66599-66606, 2021. https://doi.org/10.1109/ ACCESS.2021.3076787 
[27] Kim, Chunghun and Kim, Wonhee, "Enhanced Low-Voltage Ride-Through Coordinated Control for PMSG Wind Turbines and Energy Storage Systems Considering Pitch and Inertia Response," IEEE Access, vol. 8, pp. 212557-212567, 2020. https://doi.org/10.1109/ACCESS.2020.3040905

[28] Yao, Jun and Li, Jiawei and Guo, Lisha and Liu, Ruikuo and Xu, Depeng, "Coordinated control of a hybrid wind farm with PMSG and FSIG during asymmetrical grid fault," IEEE Access, vol. 95, pp.287300, 2018. https://doi.org/10.1016/j.ijepes.2017.08.017

[29] M. Ding and J. Wu, "A Novel Control Strategy of Hybrid Energy Storage System for Wind Power Smoothing," Electr. Power Compon. Syst, vol. 45, no. 12, pp. 1265-1274, 2017. https://doi.org/10. 1080/15325008.2017.1346004

[30] C. Kim, E. Muljadi and C. C. Chung, "Coordinated control of wind turbine and energy storage system for reducing wind power fluctuation," 2017 56th Annual Conference of the Society of Instrument and Control Engineers of Japan (SICE), 2017, pp. 1485-1489. https://doi.org/10.23919/SICE.2017. 8105714 